Supporting Information for

\title{
Development of Large-Scale Routes to Potent GPR119 Receptor Agonists
}

Richard T. Matsuoka, ${ }^{* \dagger}$ Eric E. Boros, ${ }^{\#}$ Andrew D. Brown,,$^{\dagger}$ Kae M. Bullock,,$^{\dagger}$ Will L. Canoy,,$^{\ddagger}$ Andrew J. Carpenter, Jeremy D. Cobb, ${ }^{\dagger}$ Shannon E. Condon, ${ }^{\dagger}$ Nicole M. Deschamps ${ }^{\dagger}$, Vassil I. Elitzin, ${ }^{\dagger}$ Greg Erickson, ${ }^{\dagger}$ Jing M. Fang, ${ }^{\#}$ David H. Igo,$^{\S}$ Biren K. Joshi, ${ }^{\dagger}$ Istvan W. Kaldor, ${ }^{\#}$ Mark B. Mitchell, ${ }^{\dagger}$ Gregory E. Peckham, ${ }^{\#}$ Daniel W. Reynolds, ${ }^{,}$Matthew C. Salmon, ${ }^{\dagger}$ Matthew J. Sharp,,$^{\dagger}$ Elie A. Tabet, ${ }^{\#}$ Jennifer F. Toczko, ${ }^{\dagger}$ Lianming Michael Wu, ${ }^{\dagger}$ and Xiao-ming M. Zhou. ${ }^{\dagger}$

${ }^{\dagger}$ API Chemistry Department, ${ }^{\ddagger}$ Analytical Science \& Development Department, ${ }^{\#}$ Medicinal Chemistry Department, and ${ }^{\S}$ Particle Sciences and Engineering Department, GlaxoSmithKline, 709 Swedeland Road King of Prussia, Pennsylvania 19406, United States

Table of Contents

${ }^{1} \mathrm{H}$ NMR and ${ }^{13} \mathrm{C}$ NMR of New Compounds S2-S9 
${ }^{1} \mathrm{H}$ NMR and ${ }^{13} \mathrm{C}$ NMR of New Compounds.

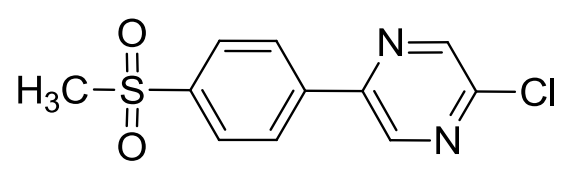

29 

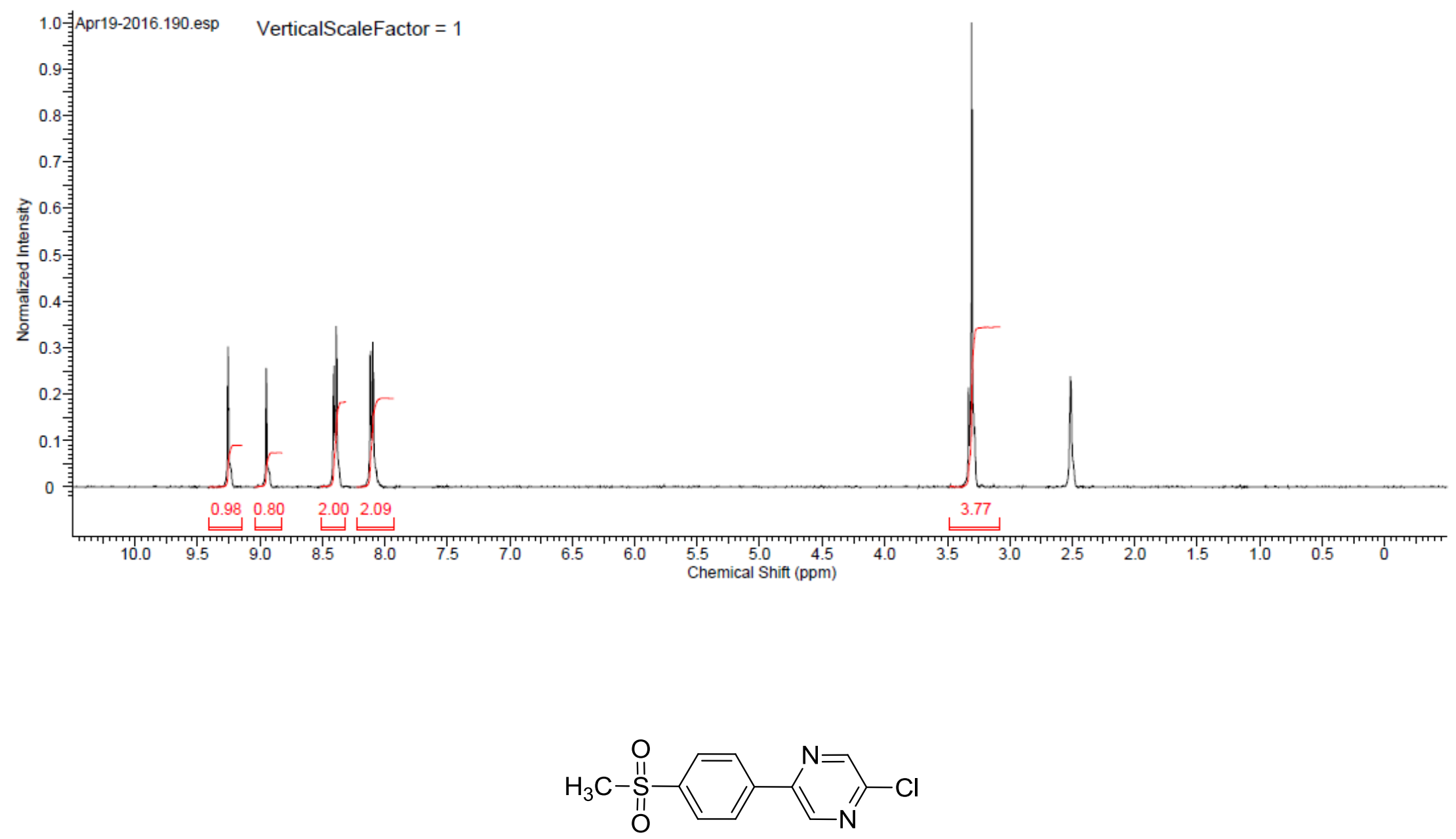

29 


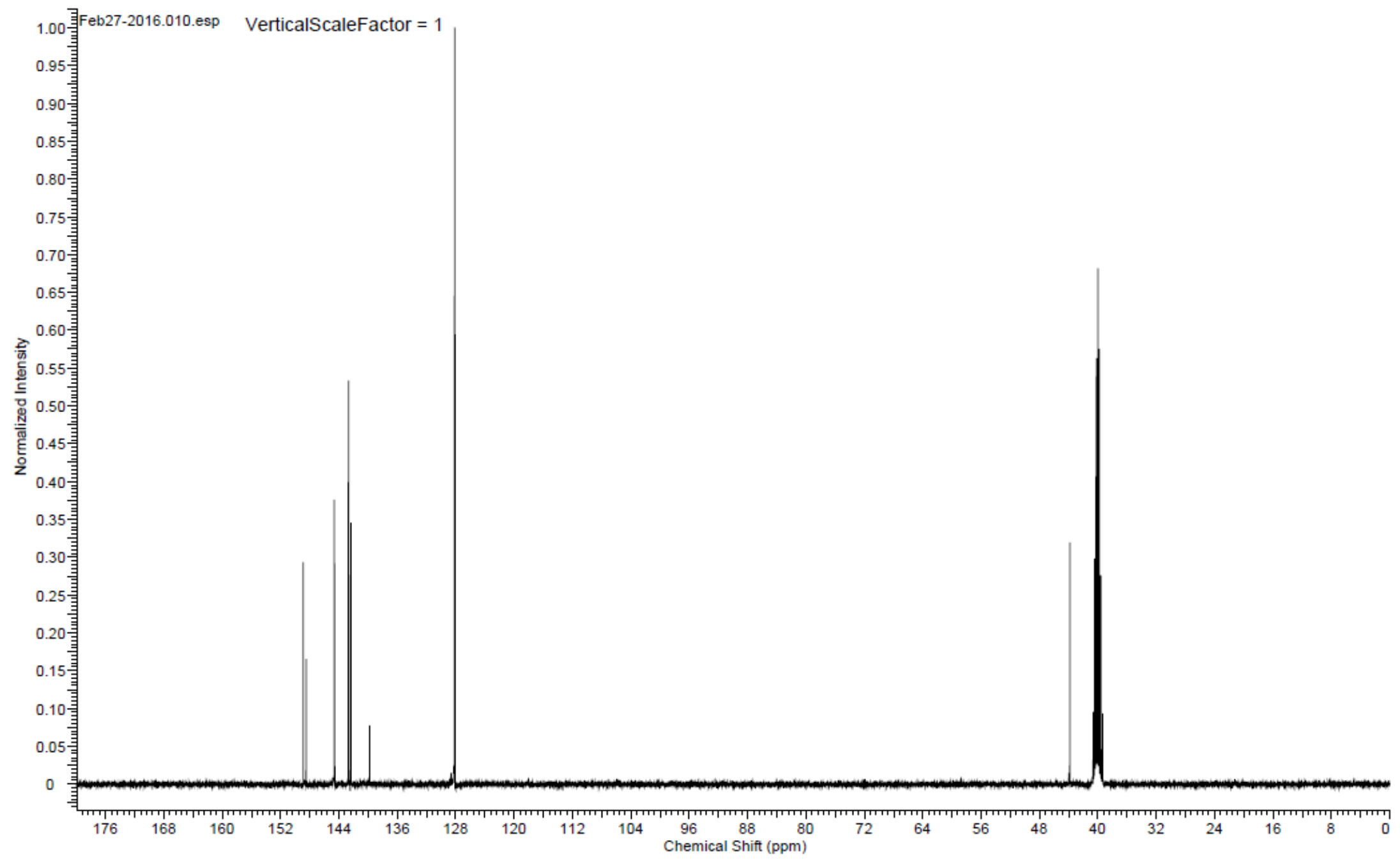



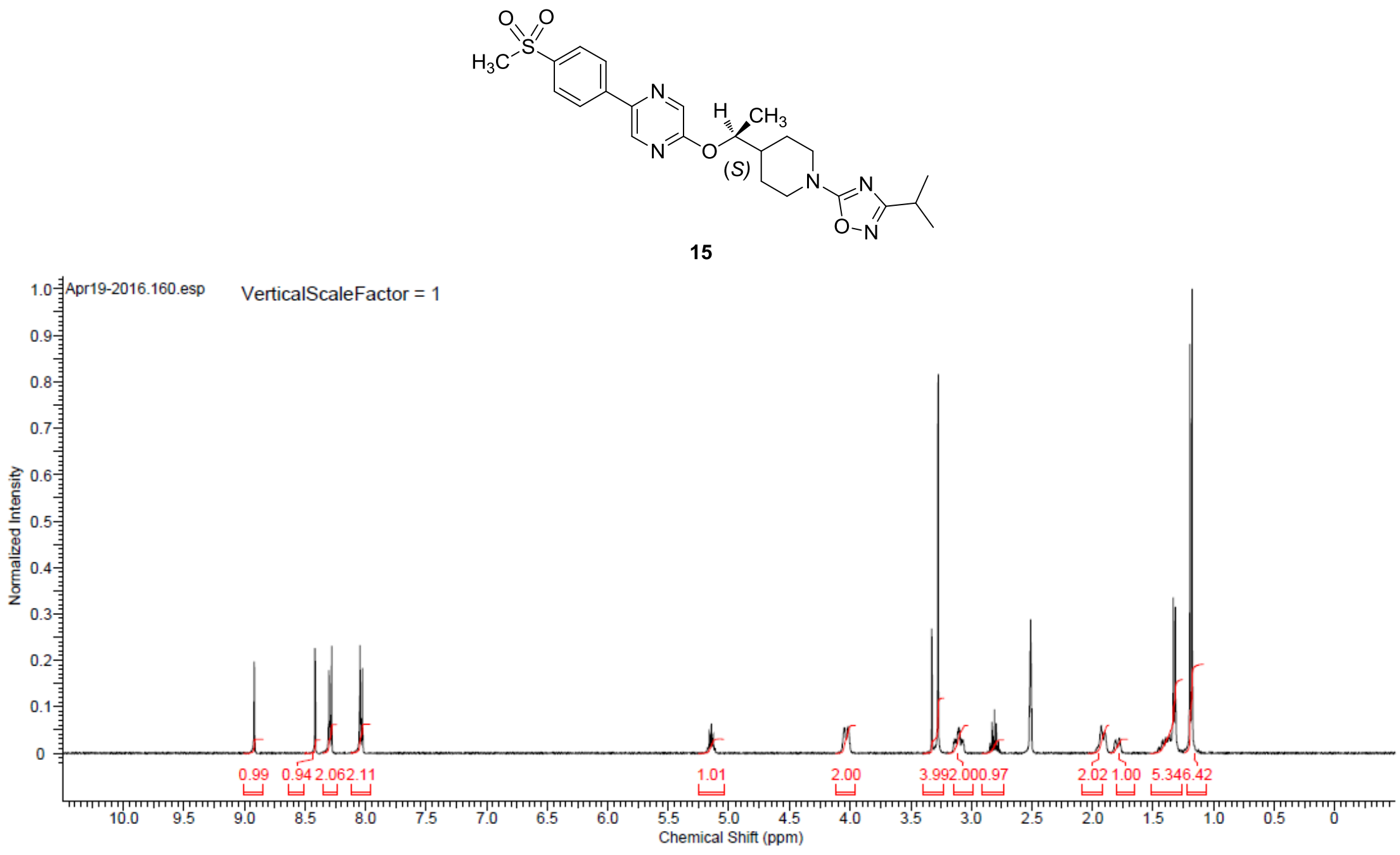

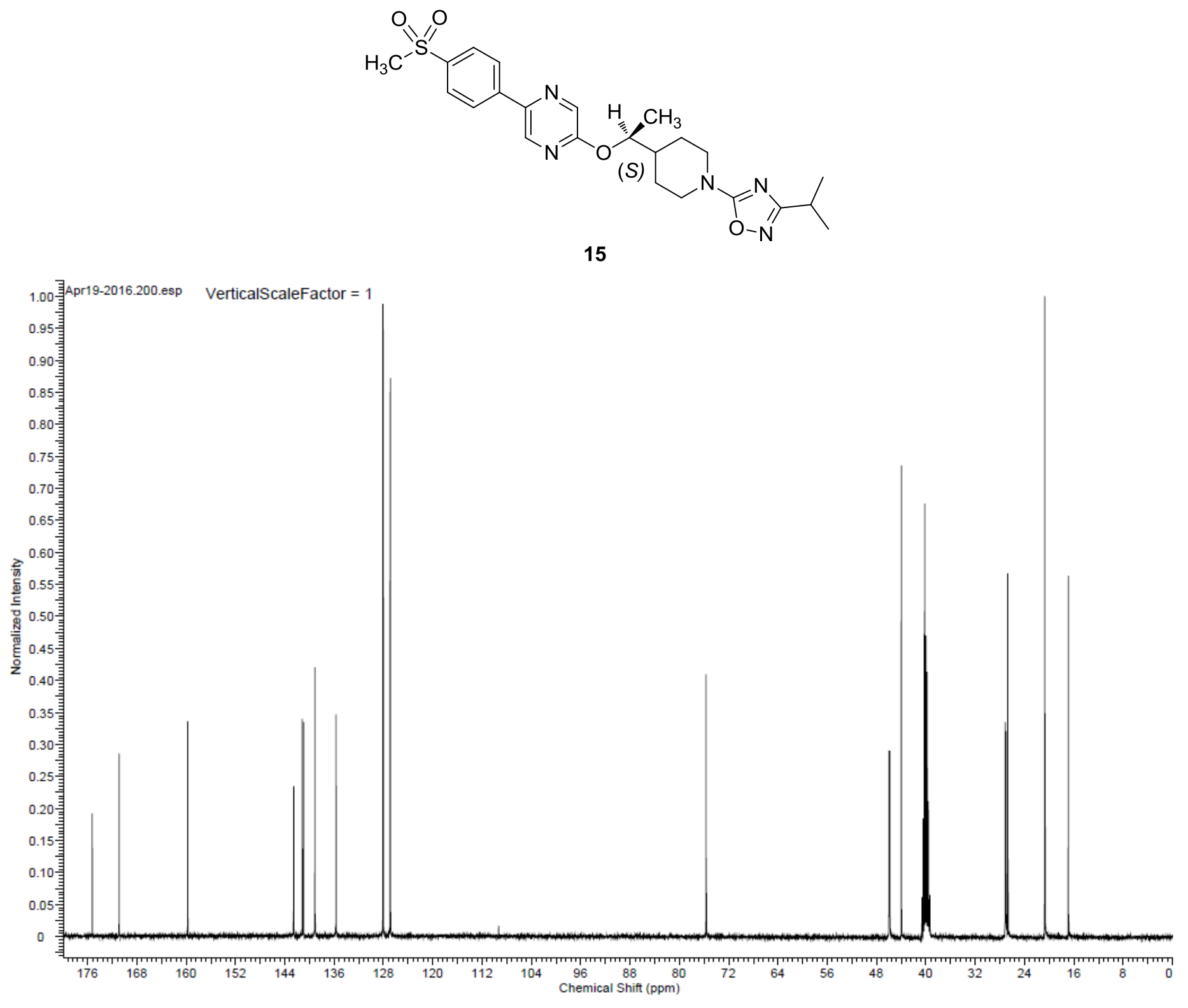


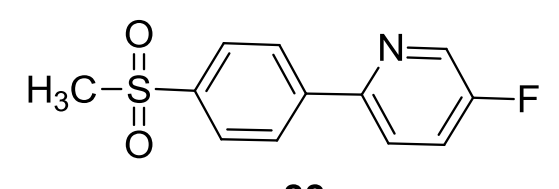

33

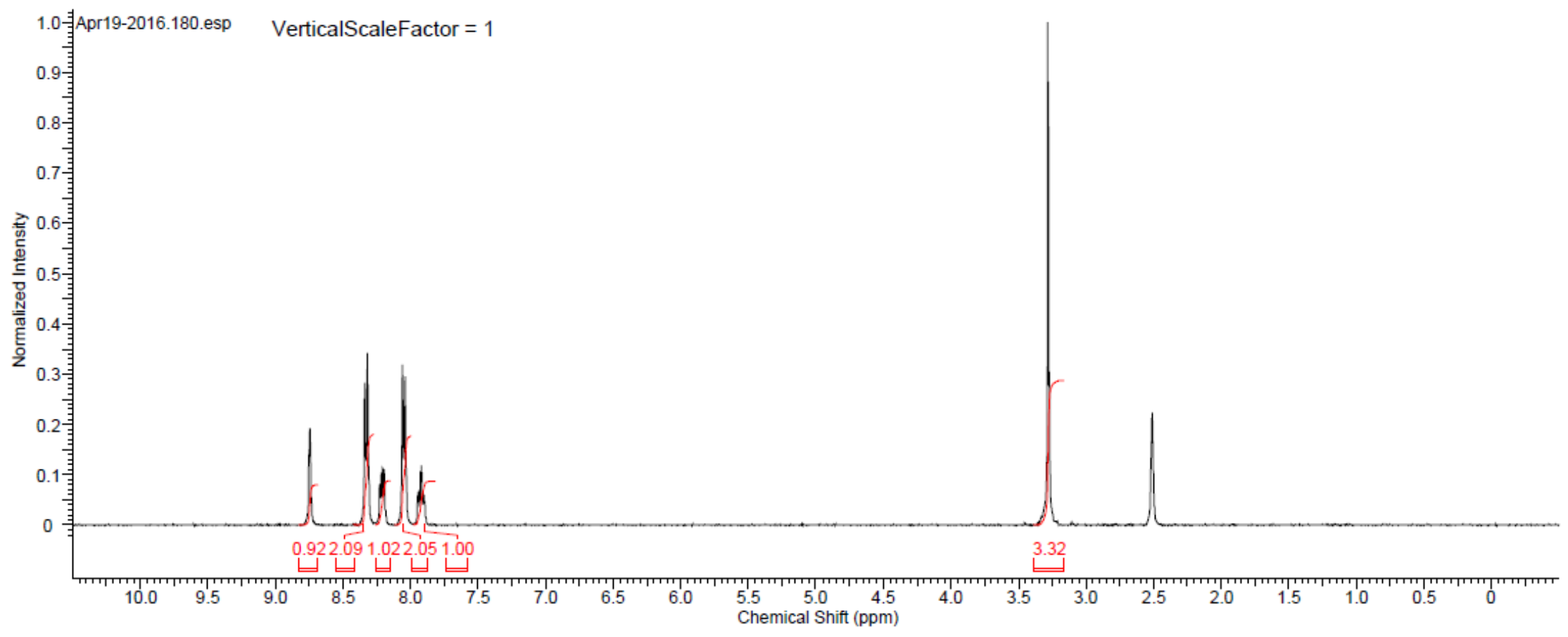


<smiles>CS(=O)(=O)c1ccc(-c2ccc(F)cn2)cc1</smiles>

33

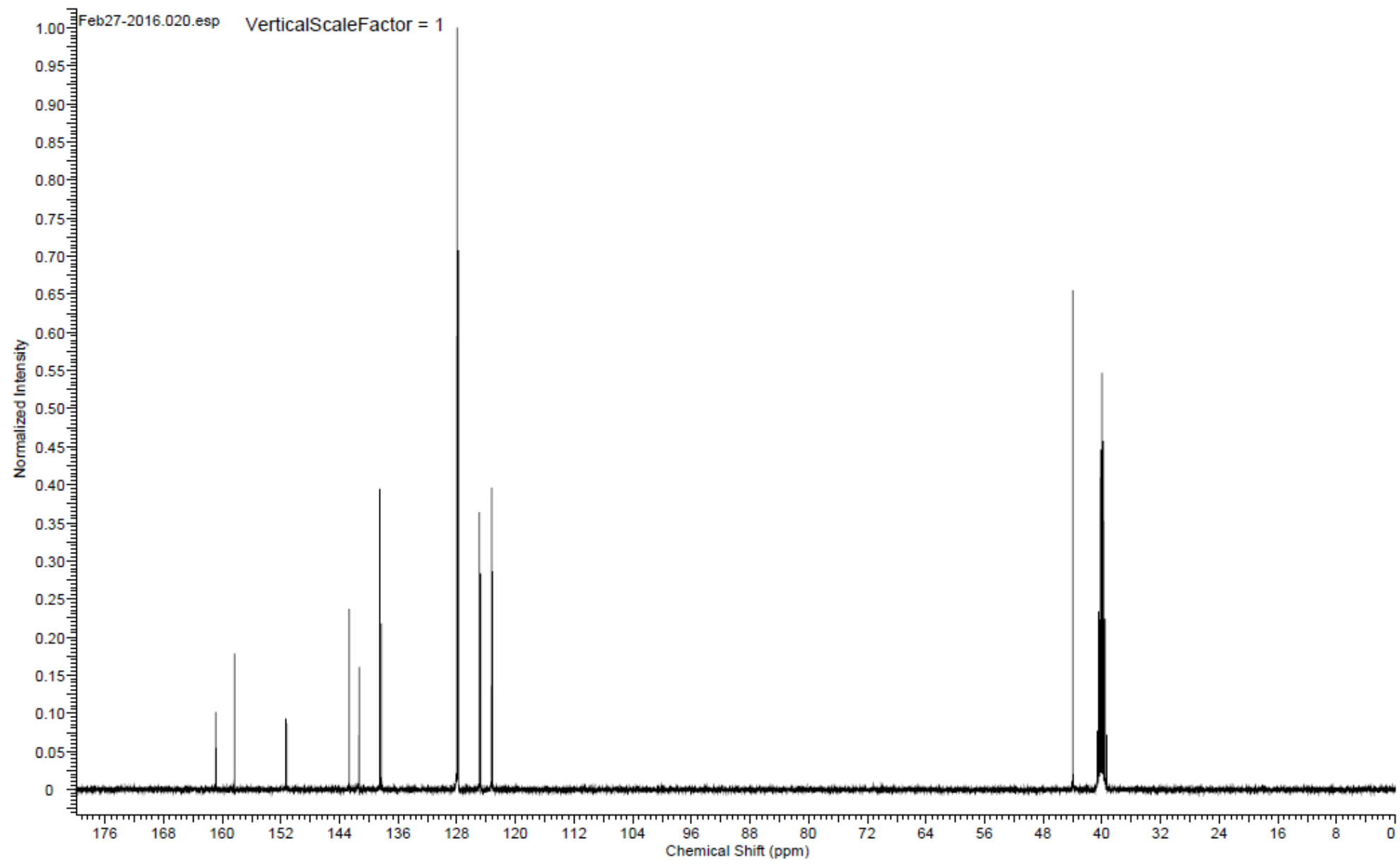

S8 

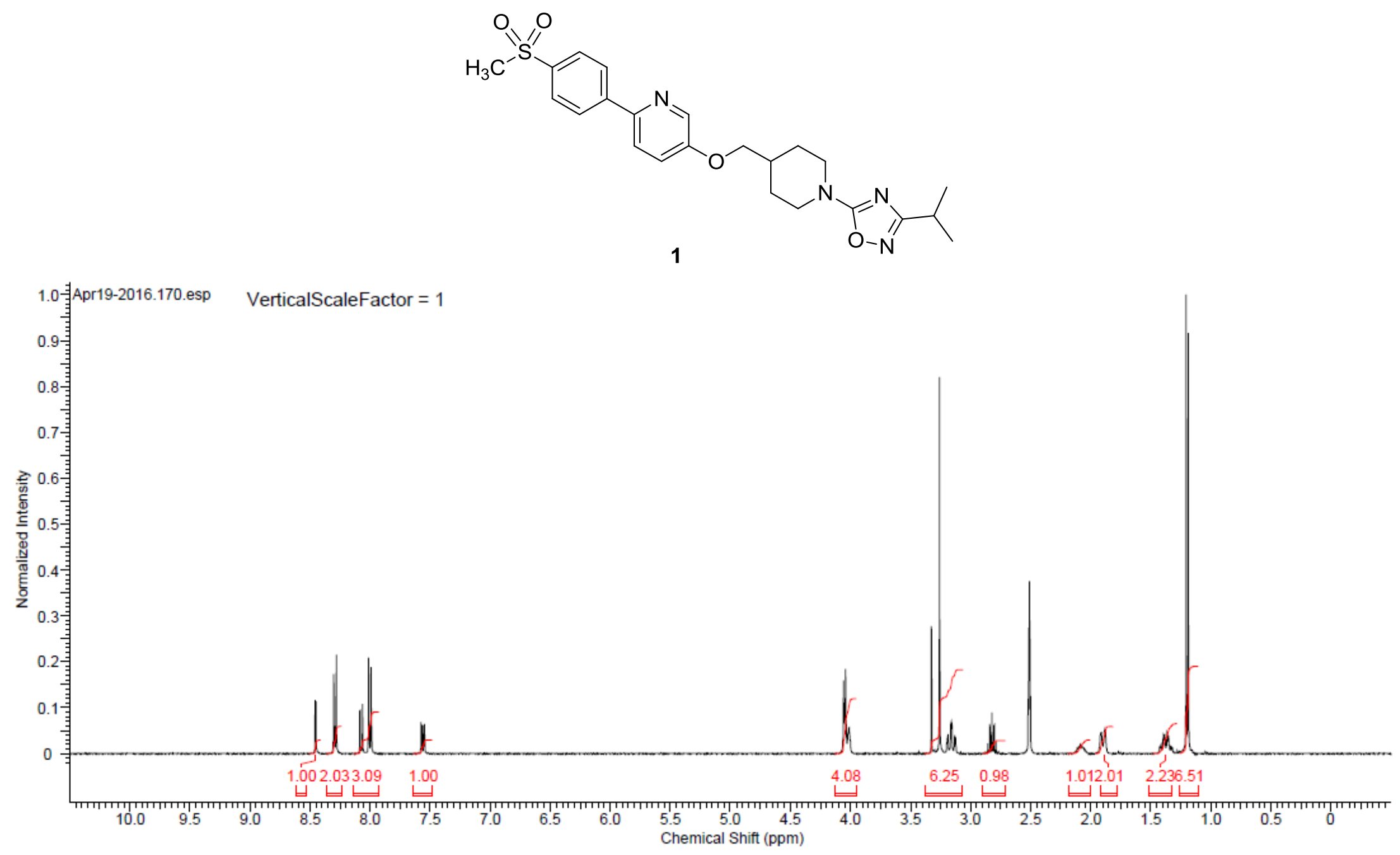

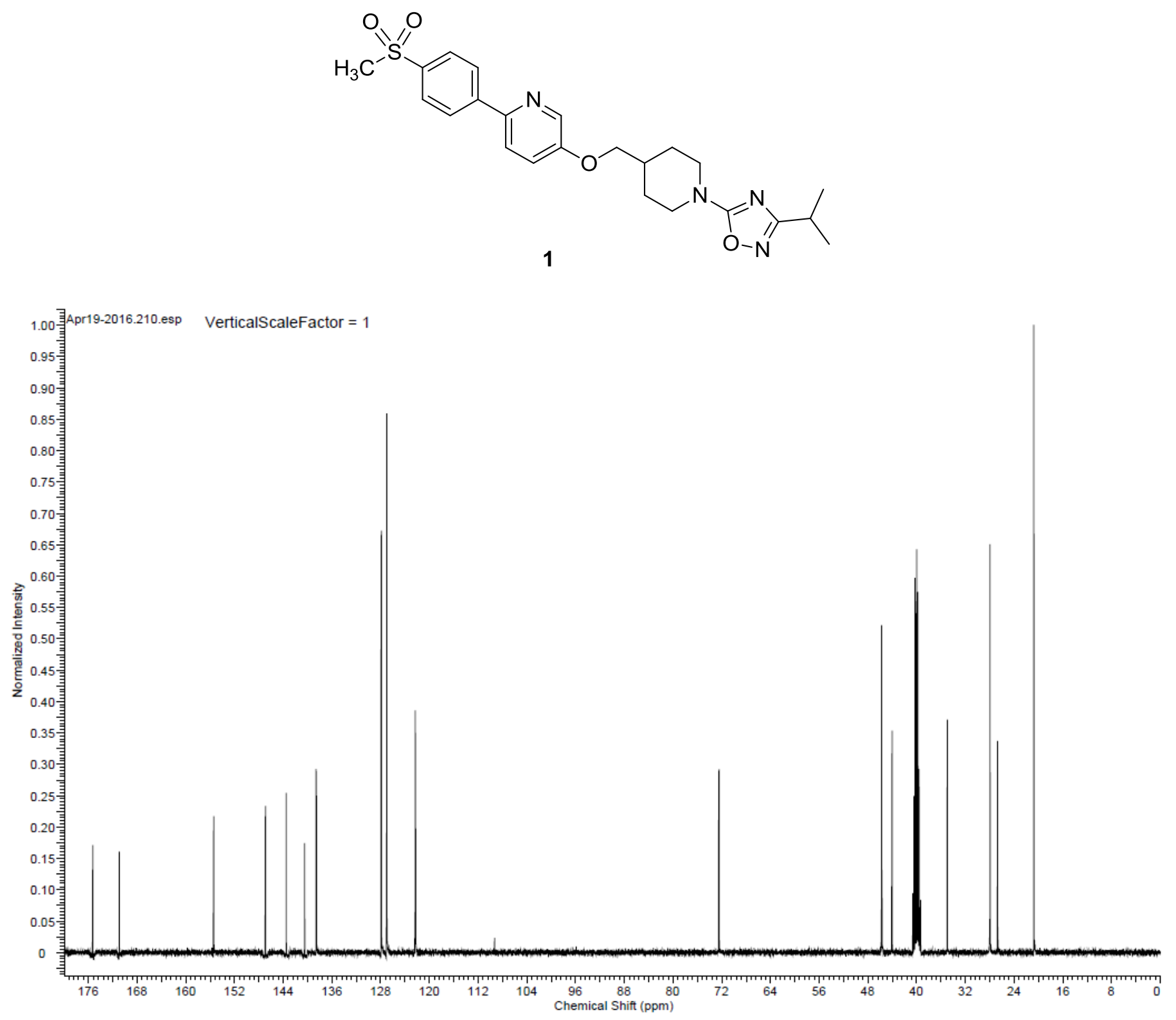